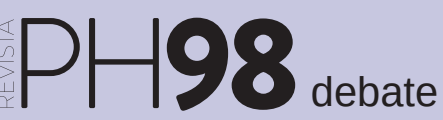

a debate ¿Hay patrimonio sin comunidad? Despoblamiento, turistificación y patrimonio cultural

| coordina Jaime Jover Báez

\title{
Barrios residenciales del siglo XX ¿Un nuevo activo para promover la vivienda como patrimonio cultural?
}

\author{
María Jesús Sacristán de Miguel | arquitecta \\ URL de la contribución <www.iaph.es/revistaph/index.php/revistaph/article/view/4477>
}

Poblar es ocupar un lugar con seres vivos para que vivan en él. La infraestructura básica para la vida del ser humano es la vivienda, mientras que si queremos poblar un lugar con especies arbóreas, para adecuar el lugar, roturamos y fertilizamos el terreno para conseguir un hábitat adecuado para esos árboles. Cuando hablamos de población/despoblamiento, estamos hablando de una infraestructura de viviendas que sirven de base a una comunidad. En este sentido, podemos establecer el concepto población como una suma de viviendas y sus habitantes formando comunidad por las relaciones que se establecen. Existen relaciones entre las viviendas, así como relaciones entre los habitantes de las viviendas; se crean vínculos físicos y emocionales, un entramado base sobre el que se van tejiendo capas de solidaridad y apoyos mutuos, que contribuyen a la creación de comunidades.

Los procesos de patrimonialización requieren de la población, o más bien de las comunidades, en lo que se refiere a la protección patrimonial, jurídica o urbanística. Se trataría de un compromiso con la ciudad, con la sociedad y con el bien común entendido como el lugar, el espacio físico soporte de las actividades de la población. Y en este sentido los procesos de patrimonialización se alinean con los retos de las nuevas agendas urbanas en sus aspiraciones de implicación en la comunidad, para conseguir una visión nueva del patrimonio más acorde con el siglo XXI; se traslada el incentivo transformador de los objetivos de desarrollo sostenible a las políticas de patrimonio para focalizar nuevos temas como son los edificios residenciales colectivos, la vivienda, en sus aspectos culturales, técnicos, sociales, económicos y medioambientales. La defensa del derecho a la vivienda impulsó la construcción de estos barrios en el siglo XX con gran innovación arquitectó-

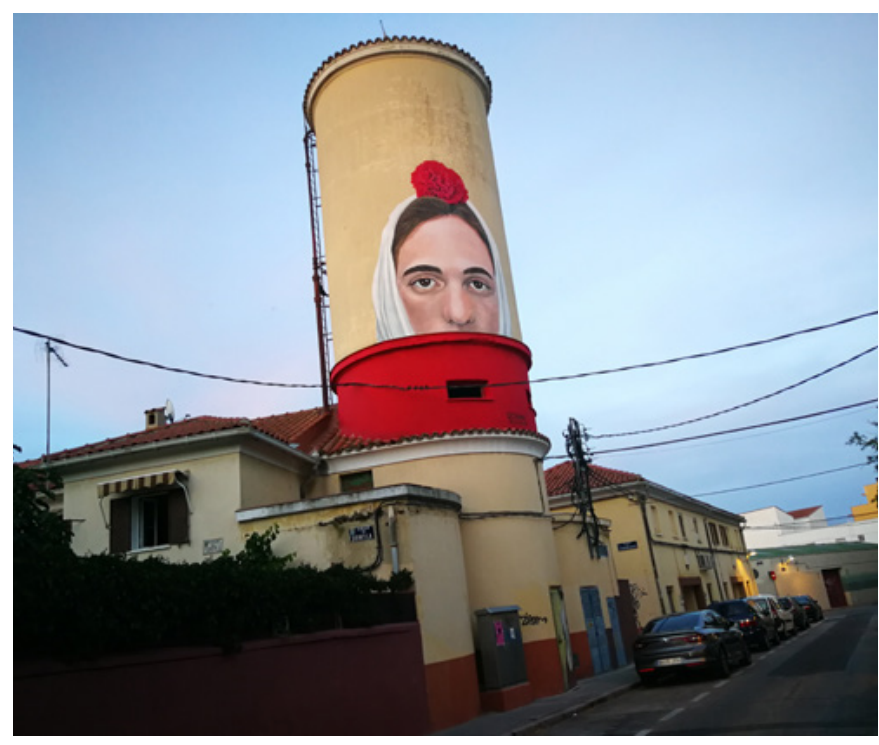

Infraestructuras de agua y energía en Colonia Tercio y Terol | foto María Jesús Sacristán, autora de todas las imágenes que ilustran la contribución

nica y urbanística, introduciendo nuevas tecnologías para mejorar las condiciones de habitabilidad, confort y bienestar de sus habitantes. La construcción de estos barrios residenciales en sus diferentes contextos es una prueba fehaciente de la civilización que los concibió, con sus características culturales, sociales, económicas y medioambientales.

¿Qué formas de poblar o procesos contribuyen a crear o destruir comunidad? Tenemos referencias de comunidades, poblados, barriadas o colonias construidas en el siglo XX por todo el territorio español. Como ejemplo de los diferentes procesos que contribuyen a destruir la comunidad, el poblado minero de San Diego en Rodalquilar (Almeria) se despobló por el desmantelamiento de los puestos de trabajo en la mina. Después, una vez que cayó en el abandono total, fue ocupado 
de forma alegal por nuevos inquilinos, y desde la administración se derribaron las cubiertas de los edificios abortando el asentamiento y la posibilidad de que floreciera una nueva comunidad. Como caso de germinación de una comunidad nacida de una ocupación alegal, el barrio de Errekaleor en Vitoria, fue también un barrio abandonado en la periferia urbana, en el que los nuevos ocupantes han resuelto hasta ahora las presiones de la administración para que abandonen el lugar con unas iniciativas innovadoras, como la instalación de paneles fotovoltaicos. Estas actuaciones hacen surgir procesos que crean comunidad a la vez que nuevas formar de cooperación y trabajo.

Como caso de barrio con procesos de transformación ante los nuevos contextos, la Colonia del Tercio y Terol en Carabanchel (Madrid) es un ejemplo de cómo la patrimonialización se ha promovido por la actividad continuada de los habitantes de las viviendas, para defender sus intereses frente a las transformaciones socio-económicas. Tercio y Terol constituye un barrio representativo de la vivienda social madrileña de postguerra, el único construido por la Dirección General de Regiones Devastadas en la capital de España. Estas viviendas se concedieron mayoritariamente a empleados asalariados (DÍEZ, 2015: 193-198). El proyecto se aprueba en 1941 por arquitectos de la Dirección General de Arquitectura, con una disposición de manzanas estrechas y alargadas para adaptarse a la topografía del terreno.

Las primeras reivindicaciones de los vecinos en los años 70, asumidas por la Coordinadora de Hotelitos, perseguían defender la cualidad de estos ámbitos de baja densidad ante la especulación del suelo por la presión constructiva, amenazados por una posible expulsión ante una revalorización del suelo y su indefensión como inquilinos. A finales de los años 70 se rehabilita la colonia, consolidando las envolventes de todas las viviendas. Más tarde el Instituto de la Vivienda de la Comunidad de Madrid, como nuevo propietario, acomete una regeneración integral de la colonia, incluyendo viviendas y urbanización, para vender las viviendas a sus inquilinos hacia 1990.

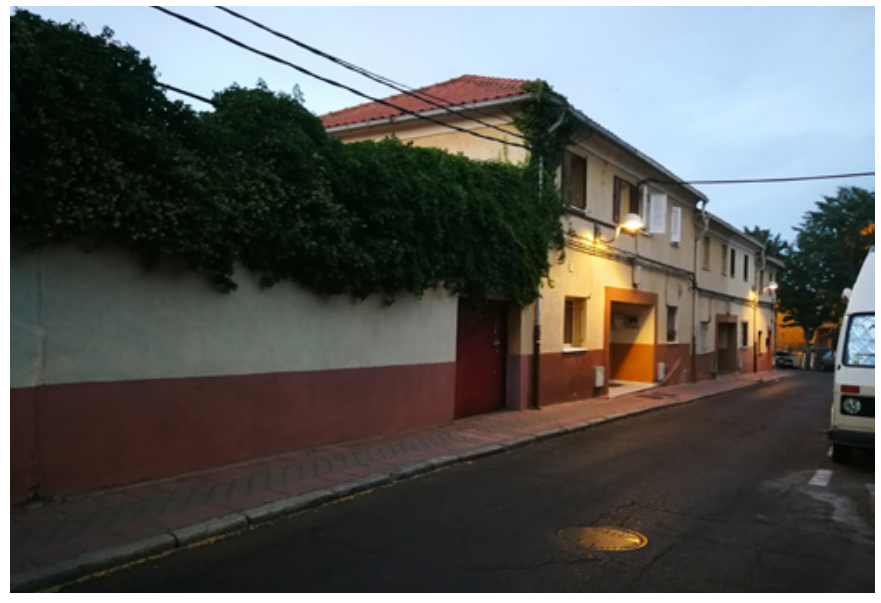

Viviendas en hilera. Colonia Tercio y Terol

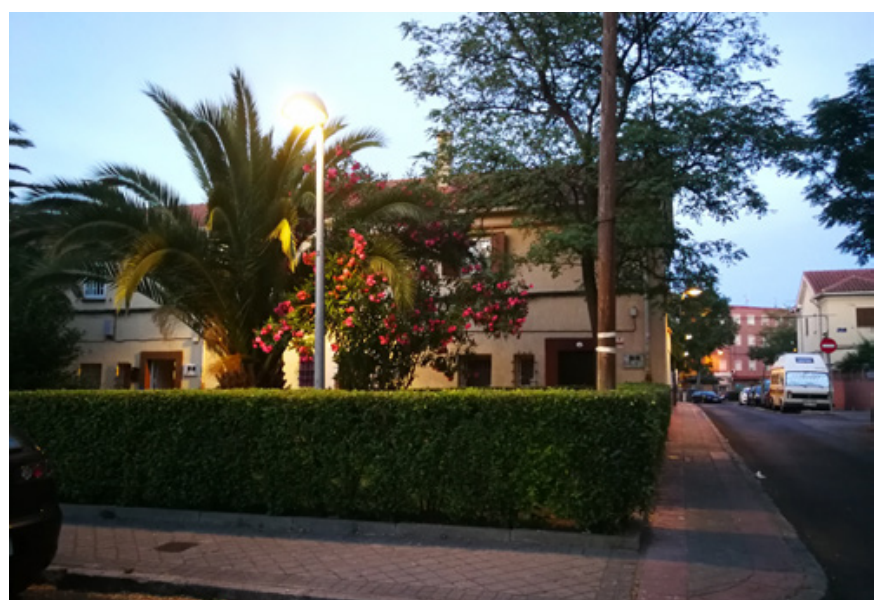

Plaza central

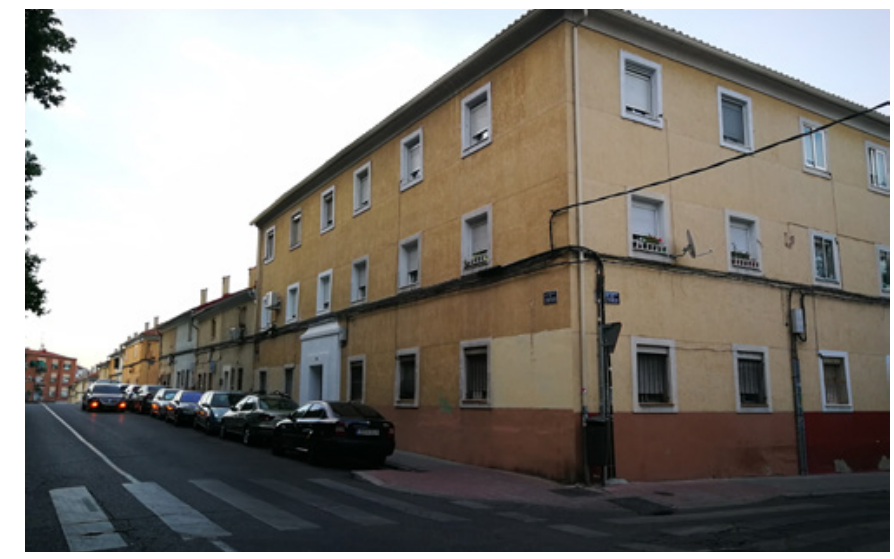

Edificios de viviendas 
a debate ¿Hay patrimonio sin comunidad? Despoblamiento, turistificación y patrimonio cultural

| coordina Jaime Jover Báez

El Plan General de 1985 se posiciona estratégicamente al defender la ciudad en su conjunto, con una ordenanza para la conservación de las colonias con cierta flexibilidad a la hora de sustituir edificios en ruina o ampliar modificando los existentes. En el Plan del 97 se cataloga Tercio y Terol como colonia histórica permitiendo usos mixtos en las viviendas, así como el aumento de las superficies construidas en planta baja o semisótanos aprovechando los patios traseros y sin modificar la volumetría general exterior, reivindicaciones de los nuevos vecinos llegados en este siglo que ahora prefieren desentenderse de las protecciones patrimoniales para ejercer como propietarios, disfrutar de mayores derechos de uso del suelo.

Las sucesivas rehabilitaciones desde la administración permitieron actualizar las viviendas conforme a los nuevos requerimientos y estándares normativos, mejorando las condiciones técnicas así como el confort y salubridad. Estas reformas, junto con los avances en las infraestructuras generales (transporte público, dotaciones cercanas, etc.) han conectado el barrio con el centro de la ciudad, el parque de San Isidro conectado con el nuevo parque lineal de Madrid Río.

En los inicios del siglo XXI se produce una renovación de la población. El envejecimiento de los residentes iniciales, junto con la relatada actualización de las viviendas y los avances en infraestructuras, facilita el cambio de propiedad en los primeros años del siglo XXI, cuando llega una población de más poder adquisitivo que los habitantes iniciales, siguiendo procesos adaptados al contexto.

Finalizar destacando cómo los procesos de creación de comunidad se articulan desde procesos que generan vínculos porque la población comparte discursos que cohesionan las propuestas de acción.

\section{BIBLIOGRAFÍA}

- AGENDA urbana española (2018) Gobierno de España, Ministerio de Fomento, 2018 <http://www.aue.gob.es/> [Consulta: 08/07/2019]

- BURDAIN, A.; MUÑOZ, J. (2018) Errekaleor tiene luz propia. Noticias de Álava [en línea], 19 de mayo de $2018<$ https://www. noticiasdealava.eus/2018/05/19/araba/errekaleor-tiene-luz-pro pia> [Consulta: 08/07/2019]

- DíEZ, A. (2015) La vivienda social como patrimonio urbano. Análisis de la patrimonialización de tres Barrios de Promoción Oficial madrileños. Tesis doctoral. Escuela Técnica Superior de Arquitectura de Madrid

- FERNÁNDEZ-GALIANO, L.; FERNÁNDEZ, J.; LOPERA, A. (1989) La quimera moderna. Los Poblados dirigidos de Madrid en la arquitectura de los años 50. Barcelona: Hermann Blume, 1989

- FERNÁNDEZ NIETO, M. A. (2016) Las colonias del hogar del e empleado. La periferia como ciudad. Tesis Doctoral. Escuela Técnica Superior de Arquitectura de Madrid. Disponible en: <http://oa.upm.es/ 4621/1/MARIA_ANTONIA_FERNANDEZ_NIETO_3.pdf>[Consulta: 08/07/2019]

- La guía de los derechos humanos a los Objetivos de Desarrollo Sostenible: objetivos, metas e indicadores. Instituto Danés de derechos Humanos. Disponible en: <http://sdg. humanrights.dk/es/goals-and-targets?page $=2>\quad$ [Consulta: 08/07/2019]

- HÁBITAT III: Agenda Urbana: Conferencia de las Naciones Unidas sobre la Vivienda y el Desarrollo Urbano Sostenible (2017) [en línea] Naciones Unidas, $2017<$ http://habitat3.org/ wp-content/uploads/NUA-Spanish.pdf> [Consulta: 08/07/2019]

- MONJO, J.; BUSTAMANTE, R.; MOYA, L. (2018) Las soluciones constructivas en las viviendas sociales de la segunda mitad del siglo XX a la luz del código técnico de la edificación. Fuencarral y Palomeras sureste, 2018, pp. 8-21

- MOYA GONZÁLEZ, L. (1983) Barrios de promoción oficial. Madrid, 1939-1976. La política de promoción pública de vivienda. Tesis Doctoral, COAM, 1983

- OVIEDO SILVA, D. La extinción de los focos irredimibles. Política de reconstrucción y control en el extrarradio madrileño. El caso de la barriada del Tercio y el Terol. En BELLVER LOIZAGA, V. Otras voces, otros ámbitos. Los sujetos y su entorno. Nuevas perspectivas de la historia sociocultural. Universidad de Valencia, 2015, pp. 101-120

- ROS GARCíA, J. M. (2015) Factores de progreso en la vivienda subvencionada madrileña de los años cincuenta. Reseña histórica y normativa. Rita: Revista Indexada de Textos Académicos, n. ${ }^{\circ} 4$, octubre, 2015, pp. 102-109 Disponible en: 
<https://dialnet.unirioja.es/descarga/articulo/5297097.pdf> [Consulta: 8/7/2019]

- SACRISTÁN DE MIGUEL, M. J. (2019a) Cuestiones sobre patrimonio y política. Hispania Nostra, 21 de junio de 2019 $<$ https://www.hispanianostra.org/cuestiones-sobre-patrimonioy-politica/> [Consulta: 08/07/2019]

- SACRISTÁN DE MIGUEL, M. J. (2019b) Agendas urbanas territoriales y ODS ¿nuevas políticas para el patrimonio? Revista PH [en línea], n. ${ }^{\circ}$ 97, junio de $2019<$ <ttp://www.iaph. es/revistaph/index.php/revistaph/article/view/4389> [Consulta: 08/07/2019]

- SAMBRICIO, C. (1997) Contemporaneidad vs. modernidad. El concurso de vivienda experimental de 1956. En La vivienda experimental: concurso de viviendas experimentales de 1956. Madrid: Fundación Cultural COAM, pp. 3-21. Disponible en: <http://oa.upm.es/1632/> [Consulta: 08/07/2019]

- SAMBRICIO, C. (2003) Un siglo de vivienda social, 19032003. Madrid: Nerea, 2003

- SAmBricio, C. (ed.) (2008) 100 años de historia de la intervención pública en la vivienda y la ciudad. Madrid: AVS Asociación Española de Gestores Públicos de Vivienda y Suelo, 2008. Disponible en: <http://gestorespublicos.org/ media/transfer/doc/publicaciones/Publicacion_100_anos AVS.pdf> [Consulta: 08/07/2019]

- VIRIZUELA, M.; RUEDA, S. (dir.) (2010) Vitoria-Gasteiz: Ciudad neutra en Carbono [en línea]. Ayuntamiento de VitoriaGasteiz;Agència d'Ecologia Urbana de Barcelona, $2010<$ https:// www.vitoria-gasteiz.org/http/wb021/contenidosEstaticos/ adjuntos/es/39/42/33942.pdf>[Consulta: 08/07/2019] 